\title{
Shaping Self-efficacy: Tracking a Group of Early Childhood Education Students for Four Years, from College to Employment in the Field
}

\author{
Nitsa Dori \\ Correspondence: Dr. Nitsa Dori, Head of the Department of Early Childhood, Shaanan Academic College, Haifa, Israel.
}

Received: May 16, 2017

doi:10.11114/jets.v5i7.2504
Online Published: June 21, 2017

URL: https://doi.org/10.11114/jets.v5i7.2504

\begin{abstract}
A "sense of self-efficacy" is defined as the process of linking knowledge to action, as the assessment of the ability to execute a behavior leading to a certain outcome. A person's perception of self-efficacy has behavioral and emotional implications. When people doubt their own abilities, they tend not to persevere, give up rapidly when encountering difficulties, and feel anxiety and negative emotional arousal when they believe they cannot cope. In terms of self-efficacy, the functions of educators, teachers, and pre-school teachers touch on at least three domains: Task, Interpersonal, and Organizational. This article documents supervision of a group of students in the Early Childhood training track including the work of novice pre-school teachers. It demonstrates what the students undergo, from the beginning of their training to employment as pre-school teachers. Based on the findings, the article reaches conclusions regarding the factors associated with student-pre-school teachers' sense of self efficacy, how each group member learns to form her own sense of self-efficacy, group interactions and achievements, whether self-efficacy is a personality trait or a formative belief, and the nature of the profiles of student-pre-school teachers with a high and low sense of self-efficacy. The article concludes that a person has varying levels of self-efficacy regarding different aspects of both his general and professional life. A person learns by dialogue with his environment and those around him, as well as with himself. Dialogue allows every teacher to further expand and improve his knowledge.
\end{abstract}

Keywords: self-efficacy, pre-school teachers, motivation, support group, students

\section{Introduction}

As a young preschool teacher, I would impatiently await the monthly meetings held at my pedagogical teacher's home. These sessions benefited me more personally than professionally, and taught me more than all the college theory lessons. The knowledge that other preschool teachers, more or less experienced, also have difficulties managing the preschool, and how they address those difficulties, helped me cope with my own personal problems in the relationships between preschool teacher-assistant, preschool teacher-parents, preschool teacher-inspectorate and local authority, and particularly with children with special needs who caused the most difficulties. The pleasant meetings were held in the evening, making them far more refreshing than afternoon sessions, after finishing working in the preschool, sitting on low chairs in the preschool of whoever's turn it was to host, and being served wafers, crackers, and cream cheese. The culinary aspect played an important role and contributed to the camaraderie. Each participant brought a warm, delicious cake or cooked dish, and it was only after we had eaten and chatted around the table that we moved to the living room, and there, sitting in armchairs, we shared both our difficulties and successes. Many years later, I copied this model when I myself became Head of the Department of Early Childhood Education at the college. I formed a group of students who lived close to my Netanya home who came to my home monthly. I summarized each session in writing - what each of them reported, their challenges at the college, in teaching practice, and later in their first two years as a preschool teacher. The guidance process continued for four years, and I believe the documentation should be publicized, to learn and teach the nature of the self-efficacy process each student experiences from the start of her college studies until becoming a preschool teacher.

\section{Self-efficacy}

The concept of self-efficacy was coined by Bandura (1997), who viewed it as crucial for explaining human behavior. Bandura defines self-efficacy as "the belief in one's capabilities to organize and execute the courses of action required to manage prospective situations". Meaning, the extent to which the individual believes he generates various events and situations that "happen" to him. Someone described as having high self-efficacy tends to persist in striving to reach his desired goals more than someone characterized by low self-efficacy, since he believes there is a reason to persist - "it 
depends on me, and not on someone or something outside me". Self-efficacy can be developed by success in performing tasks, studying behavioral models, verbal persuasion, and high positive physiological and physiological arousal.

Perceived self-efficacy has behavioral and emotional effects. People who cast doubts on their ability will tend to invest little effort and quickly give up should they encounter difficulties, and feel anxiety and negative emotional arousal in situations in which they believe they cannot cope. Moreover, self-efficacy concerns a person's belief in his ability rather than his objective capabilities.

The social cognitive revolution in psychology, during the 1950s and 1960s, also discussed motivation, and shifted attention from basic and subconscious needs and from reinforcement and punishments, to cognitive processes. One of the most important developments in this area was the understanding that motivation includes the individual's expectations of the results of his behavior. Various definitions of these expectations have become central concepts in explaining human behavior. Kaplan and Asor (2001) explained that self-efficacy is belief in one's ability.

Bandura (1986) formulated the idea and laid the theoretical basis for the concept of "sense of self-efficacy", and defined it as a process connecting knowledge and action, estimating the ability to behave in a way that leads to a particular result. Expanding the definition to belief in the ability to mobilize motivation, cognitive resources, and actions needed for mastering the requirements of a task, emphasizes the thought process.

Skills, good capabilities, and a high sense of self-efficacy are needed to effectively realize internal resources, particularly when carrying out complex tasks, despite skill levels and individual capabilities not necessarily being commensurate with the person's perception of how he can use them in various situations. Self-efficacy is an evaluation, judgment, and mastery process that creates an estimate of how a person thinks, feels, and acts, and significantly contributes to motivation and achievements.

Bandura (1997) lists five processes based on accumulated experience through which a general perception of self-efficacy is formed:
A. Similar skills needed for a variety of activities.
B. Simultaneous development of skills in various fields.
C. Mastery of self-regulation mechanisms.
D. Coping skills that can be generalized, and allow the individual to exercise control when under pressure.
E. Structuring common success behaviors cognitively in various activities.

Ashton and Webb (1986) link efficacy in teaching to the teachers' activities, effort, and persistence.

Teachers with low efficacy will refrain from difficult activities in line with their abilities, not persist with children with difficulties, and will demonstrate minimal efforts and less variety in teaching processes.

Teachers with high efficacy will develop challenging activities and help challenging students. These activities will advance student learning and strengthen teacher efficacy and motivation. Likewise, it was found that teachers with good efficacy had a positive classroom atmosphere, supported students' ideas, and responded positively to needs linked to praises, individual attention, checking the students' progress and achievements.

Friedman and Kass (2000) expanded the concept's definition in line with Cherniss (1993). Cherniss suggested that teachers' sense of efficacy should be examined in three functioning domains: (1) Task Domain - the teacher's ability to improve student grades, and includes such aspects as mastery of knowledge, lesson planning and execution, and correcting student performance; (2) Interpersonal Domain - the teacher's ability to work harmoniously with others in his professional environment; (3) Organizational Domain - the teacher's ability to influence the organizational decision-making process, contribute to it, and draw strength from it. The main innovation in this scale, constructed by Friedman and Kass (2000), is expanding understanding of the teacher's self-efficacy beyond the classroom setting. Teacher efficacy is also constructed, according to these findings, from the ability to maintain good interpersonal relations with others in the school organization (particularly the principal) and influence what occurs in the school. Understanding that the teacher's functioning is comprised of at least three areas (task, interpersonal, and organizational), allows us to organize the research findings in this article around a consolidated structure, and examine similarity and difference between the findings. Likewise, based on the findings, the article summarizes the factors linked with the student preschool teacher's sense of efficacy, and the profile of the student preschool teacher with a high sense of efficacy.

This article will attempt to address the following questions:

- How much do the early childhood education colleges think about the factors linked with the professional sense of efficacy of the future preschool teacher, and ensure the curriculum increases this feeling? Do the colleges really develop 
the student preschool teachers' sense of efficacy in the task, interpersonal, and organizational domains, and what weight does each of these areas occupy in the curriculum?

- How can the preschool teachers' sense of efficacy be developed, particularly in the organizational and interpersonal domains? Did the monthly meetings for student preschool teachers lead to the acquisition of interpersonal capabilities and learning about organizational behavior?

\section{Methodology}

The article is based on following seven students of Early Childhood Education from the Shaanan Teachers' College in Haifa, Israel, for four years, during monthly meetings. During the sessions, each student raised her difficulties and successes regarding her classroom college studies and teaching practice in the preschool. The group was heterogeneous regarding the seniority of each student in her studies or later, when working as a preschool teacher. The information for the article was collected and documented from each student, and reflected each one's abilities in educating children in preschool, her relationship with the preschool assistant, and her interaction with the parents. Each student's comments were arranged in the table according to three parameters: task, interpersonal, and organizational. Following an analysis of the findings in the table, conclusions were drawn.

\section{Summary of the Meetings in a Parameter Table}

To answer these questions, the meetings are summarized in tables. One table, divided into three parameters of types of self-efficacy functioning: task, interpersonal, and organizational, has been prepared for each year. The participants are identified by initials. To gain general information from the efficacy map about all the participants - the examples in italics show a lack of efficacy or low self-efficacy in light of difficulties in specific functioning, and the examples in Roman type indicate high self-efficacy in light of success in specific functioning. After viewing this data, we can progress to an individual analysis of each participant, regarding her sense of efficacy in the three parameters over the entire time period.

\section{$4.12012 / 13$}

The meetings were first held in 2012/13 when all participants were still students at various stages of their teaching studies. Several more participants, who later dropped out of the meetings, are therefore not included in Table 1. Table 1 includes only those three students who continued to attend the meetings in later years, to show their self-efficacy development.

Table 1. 2012/13

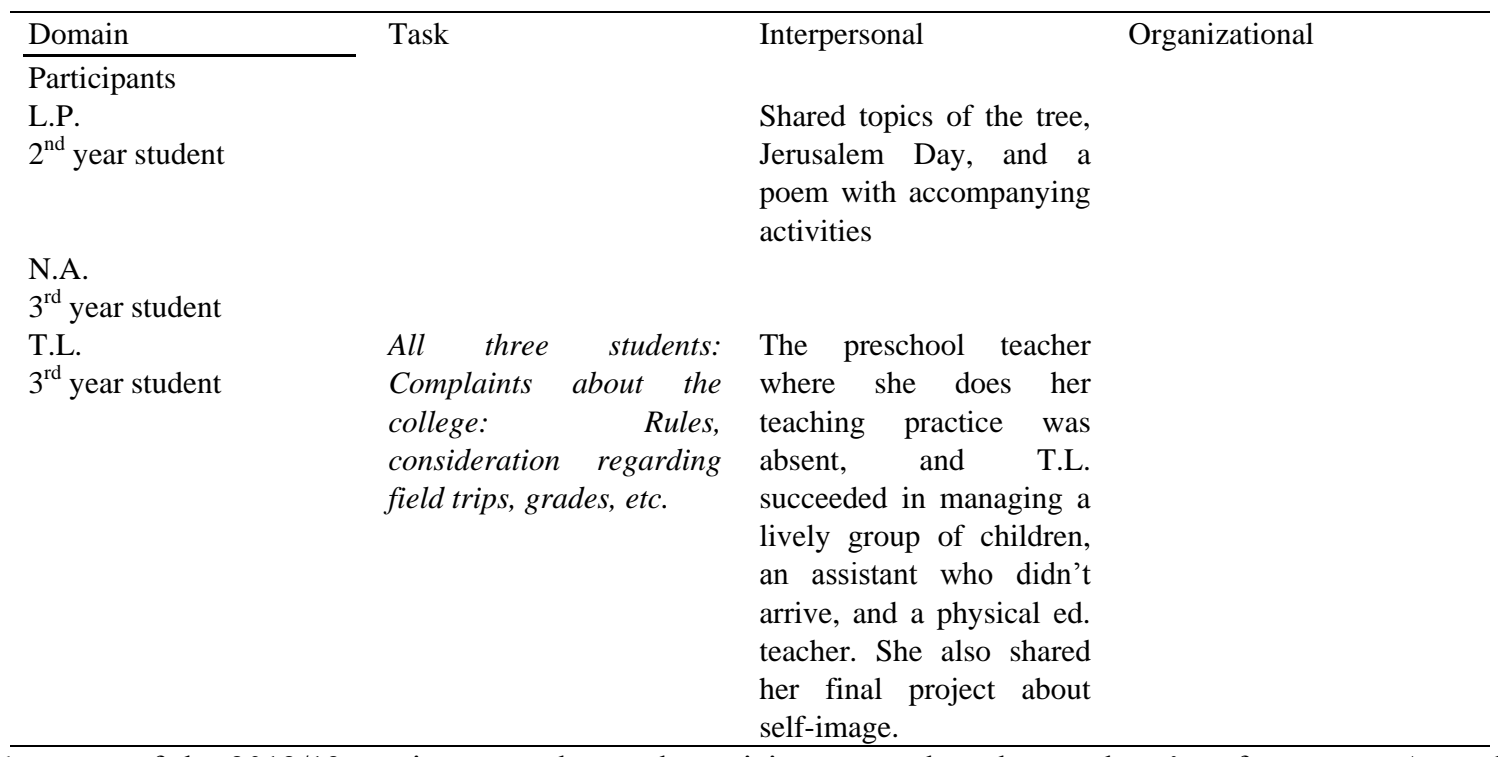

The advantage of the 2012/13 sessions was that each participant saw the other students' performances. According to studies by Bandura (1997) and Barone, Maddux, and Snyder (1997), attempts at learning while studying a model, or learning by imitation, are considered one of the sources of self-efficacy, with watching other people's successful attempts possibly contributing to better self-efficacy, and the converse.

We can summarize 2012/13 by saying the greatest difficulty focused on the college and included complaints about projects, grades, and lecturer-student relations. There was no reference to the actual teaching practice. During this year, the students mainly received tools to cope with the scholastic tasks, while focusing on a model for self-regulation while 
studying (Katz \& Frish, 2013). The students learned to work cooperatively, when and how to study, how quickly to advance, and thus prepared themselves for study skills and strategies that would allow them to develop as a learning community. The senior students in the group, T.L. and N.A., encouraged L.P., who was a year younger than them, and advised her on how to cope with the various college tasks. While studying independently, the students also learned how to nurture independent learners in the preschool, develop cognitive skills and nurture thinking, and encourage children's problem-based learning. They themselves experienced addressing a subject they liked and were curious about, and how it led to them listening more carefully in class; and how they cope with a less enjoyable subject or lecturer who teaches in a non-challenging manner that leaves them as passive learners who become bored in class and do other things. It was a year that taught them about their professional lives as future preschool teachers. Some complaints were about the college's rules that they considered "inflexible". These complaints indicate a certain study crisis that they experienced, a crisis that only those with motivation to overcome it, succeed, and cope with study challenges would emerge from, or, in other words: only those with a higher level of self-efficacy than others in the cognitive, behavioral, and emotional domains. In the cognitive domain, it is easier for students with high levels of knowledge, memory, and spoken and written language. In the behavioral domain, it is easier for students who can envisage the external reward for their efforts: earning a degree, and knowing it carries a price. In the emotional domain, it is easier for students who can delay gratification, be flexible and creative, and reduce pressure and anxiety (Barone et al., 1997).

In addition, the difficulties they complained about regarding their studies, particularly the rules and regulations, will be built into a better future when they will need, as preschool teachers, to teach preschoolers rules and regulations to maintain the best possible preschool climate.

\section{$4.22013 / 14$}

Table 2. 2013/14

\begin{tabular}{ll}
\hline $\begin{array}{l}\text { Domain } \\
\text { Participants }\end{array}$ & Task \\
$\begin{array}{l}\text { A.A., 2 } \\
\text { student }\end{array}$ & $\begin{array}{l}\text { Shared experiment she } \\
\text { conducted with oil floating } \\
\text { on various liquids }\end{array}$ \\
$\begin{array}{l}\text { L.P., } 3^{\text {rd }} \text { year } \\
\text { student }\end{array}$ & $\begin{array}{l}\text { Successfully substituted for } \\
\text { preschool teacher for three } \\
\text { days }\end{array}$
\end{tabular}

N.A., preschool teacher during her internship year

T.L., preschool teacher during her internship year

Shared a special Family Day activity she organized with the physical education teacher, ending with breakfast for the children and parents

A difficult struggle with a child not yet toilet-trained, a plague of mice, coping with a new immigrant child from France who appears neglected (sometimes comes without shoes or underpants).
Interpersonal

Shared how she taught the children to use glue, and the importance of a personal story at the beginning of each morning circle time (enabling the children to feel a connection to the topic)

Shared how she manages to elegantly answer the parents' complaints, and direct them to helping the preschool's needs.

Her "rotating" preschool teacher does whatever takes her fancy without asking N.A., particularly regarding classroom bulletin boards.

Cooperation with the mother to toilet-train the child. Coping with parental complaints about the mice, an uncooperative assistant, and the mother of the new immigrant child from France who suffers from physical neglect by the parents. This mother came with all her children to the workshop T.L. had prepared, and they took over all the materials intended for all the parents and children.
S.D.,

preschool
Shared many materials she had prepared in the preschool, showed pictures she had made
Organizational

The municipality has not yet hung carpet boards on the walls, and this makes things hard for her.

The municipality has not yet hung carpet board in the preschool; cranes working over the heads of the children in the yard; her frustration regarding her repeated, unanswered requests to the municipality (carpet board, extermination, cranes).

Shared that the inspector observed her and left the preschool without saying a word. T.L. ran after her, and the inspector reprimanded her and said she shouldn't have left the children. T.L. called her in the afternoon and was given negative feedback. T.L. was badly hurt.

A second conversation patched things up between them. 
teacher during

her internship

year herself, shared the fine motor skills portfolio

case she had made for children with difficulties in this area, her success in pacifier weaning for circle time, her curricula: healthy nutrition (brought the food pyramid she had prepared and her Chayuta Briuta ${ }^{1}$ doll). Shared the secret of preparing sponge trees from a workshop she had participated in, and also emailed materials to everyone after the meeting.

According to Shimoni and Baxter (1996), working with parents is the most complex and difficult part of the preschool teacher's role. The difficulties in creating a relationship sometimes cause frustration to both teachers and parents, with each side not always understanding why they are uncomfortable. Thus frustration escalates, resulting in loaded and tense relationships. Such a relationship often leads to a stereotypical view of "parents", and the preschool teacher talking to them harshly. Since this adaptation process is not simple and clear to every preschool teacher, and the definition of her role with the parents is very vague, preschool teachers who leave college unsurprisingly encounter many difficulties. The American National Association for the Education of Young Children (NAEYC) published a document listing five principles for training preschool professionals (Hyson, 2003). The second principle discusses creating a relationship with the families. According to this document, the students must learn about families during every training program. They need to know and understand the characters of families, learn to support and strengthen families by creating a mutual and respectful relationship, and encourage parental involvement in children's development and learning. The document also states that students must understand that when they are unsuccessful in involving parents, they must not leave it at that that, but it is important to examine whether the preschool teacher used the appropriate approach and means for those parents. Thorough understanding of the family's economic, cultural, and social situation will also lead to a better understanding of the children's lives. There is sometimes a gap between how the teacher and parents perceive her role. Shimoni and Baxter (1996) note that this gap often leads to the preschool teachers taking offence, since they feel parents do not sufficiently appreciate their work. The interviews with the preschool teachers show two issues connected to this gap: the teacher's self-perception regarding her knowledge of child development, and perception of her position as complex and difficult.

In 2013/14, three participants began their internship year and most began to struggle with one of the greatest difficulties in the preschool teacher's work: working with parents. Table 2 shows the three interns experienced different levels of self-efficacy: T.L. experienced the greatest difficulties in the interpersonal domain, and found organization and coping difficult with both parents and the local authority; N.A. mainly experienced difficulties regarding the organizational domain with the local authority that did not address her needs, and with her "rotating" 2 preschool teacher. However, she also experienced successes in the interpersonal domain - her relationships with parents, and in the task domain - coping with discipline difficulties among the children. S.D. had a higher level of self-efficacy and reported great success particularly in the interpersonal domain - sharing pedagogical materials she created in the preschool with the other participants, and in the task domain - with her professional work with the preschool children. In light of their reports regarding the task and interpersonal domains, students L.P. and A.A. demonstrated a high level of self-efficacy this year.

$4.32014 / 15$

Table 3. 2014/15

\begin{tabular}{|c|c|c|c|}
\hline Domain & Task & Interpersonal & Organizational \\
\hline \multicolumn{4}{|l|}{ Participants } \\
\hline $\begin{array}{l}\text { A.A., } \\
\text { student }\end{array} 3^{\text {rd }}$ year & $\begin{array}{l}\text { Shared her final project: a musical } \\
\text { corner in the preschool using materials } \\
\text { from nature. }\end{array}$ & $\begin{array}{l}\text { Shared a Passover group game that imitates the } \\
\text { seller-buyer relationship. } \\
\text { Shared preschool activities with rhythm sticks, } \\
\text { and learning the concept of "probability". }\end{array}$ & \\
\hline $\begin{array}{l}\text { G.S., } 2^{\text {nd }} \text { year } \\
\text { student }\end{array}$ & & $\begin{array}{l}\text { Shared her visit to the Kibbutz Lavi preschool } \\
\text { and her impressions, yard games she had } \\
\text { developed. }\end{array}$ & \\
\hline $\begin{array}{l}\text { L.P., preschool } \\
\text { teacher during } \\
\text { her internship }\end{array}$ & $\begin{array}{l}\text { A challenging struggle with violent } \\
\text { children }\end{array}$ & & \\
\hline
\end{tabular}

${ }^{1}$ From the Ministry of Education educational series about nutrition.

${ }^{2}$ The rotating teacher works one day a week, on the regular preschool teacher's day off. 


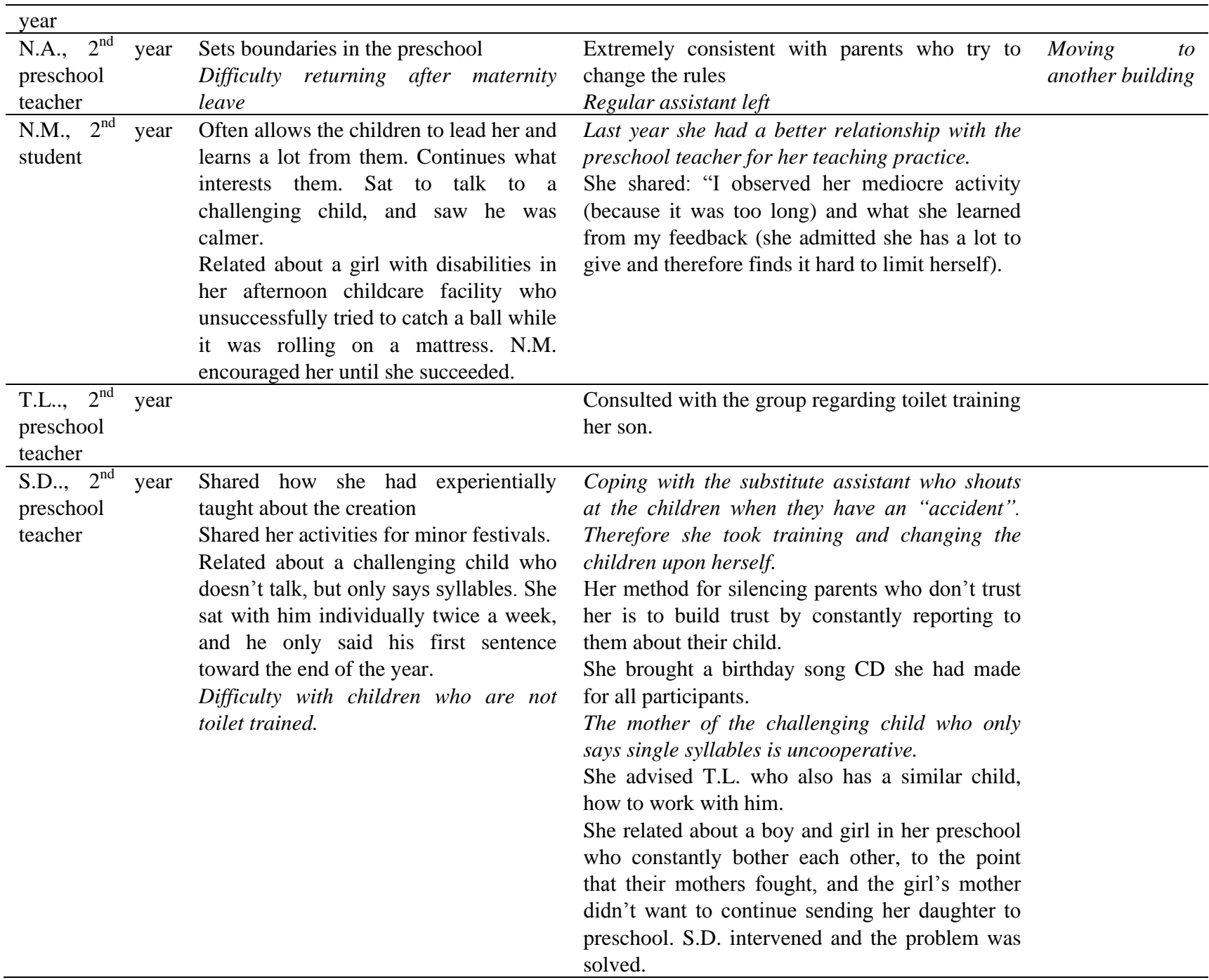

There is agreement in the professional literature that mainstreaming children with special needs is a significant reform in the concept of education (Ruijs \& Peetsma, 2009). The rehabilitation of the mainstreamed child, advancing his independence, and adapting and preparing him for the best possible social and professional life by utilizing his abilities to the greatest possible extent, required many educators to expand their knowledge and combine psychological fields in their teaching - areas they had not chosen to work with. Studies show that success in mainstreaming, and its implementation is firstly dependent on the views, perspectives, skills, readiness, and knowledge of the teacher and educator (Cohen \& Leyser, 2006). Most educators support mainstreaming policies, but argue they lack the required time, expertise, training, and sources to effectively implement them (Almog \& Shechtman, 2004; Talmor, Reiter, \& Feignin, 2004; Timor, 2004). Teachers with a higher efficacy perception tended to take helping approaches, such as praising and giving reinforcement, and tended to ascribe the child's problem to the reciprocal relationship between him and his environment. In contrast, teachers with a low efficacy perception tended to more frequently view the problem as the student himself and preferred more limiting approaches, such as sending the student for therapy outside the regular classroom.

Table 3 shows that in 2014/15 the group sessions were characterized primarily by struggles with challenging children with special needs: ADHD, learning disabilities, and violence. Three students joined the group: A.A. and G.S. who reported successes and had a high level of self-efficacy, and N.M., who had a slightly lower level of self-efficacy, and reported difficulties forming a relationship with the mentoring preschool teacher. S.D., L.P., and N.A., who were already working as preschool teachers, had a medium efficacy level, and related both difficulties and successes in the interpersonal and task domains. We see a certain drop in S.D.'s high self-efficacy level from the previous year, particularly in the interpersonal domain, and, conversely, T.L.'s increased efficacy, since she doesn't report any difficulties at all. 


\subsection{Letter from L.P. at the End of the 2014/15 School Year}

It's true I gave a brief summary during the wonderful meeting we had, but there is more... I got to know you from when I began at the college, and we were together for four years. This is clearly not a goodbye, but an opportunity for me to tell you what I feel. Thank you for always believing in me. Thank you for the real and significant learning. Thank you for listening when things were hard, for the support, encouragement, and good advice. Thank you for the support, the interest you showed, and the big hug for Hadar. I don't know how to thank you and appreciate everything!!! None of this should be taken for granted, and I am tremendously appreciative and grateful for everything!! Carry on containing, listening, giving advice and help, and being such a special woman!!! Thank you for everything.

\subsection{The Reply}

I want to thank you so much for your warm and moving words. The truth is you got in first, because I wanted to write a few words personally to every one of you, and while I was switching on the computer, I said to myself, 'I'll start with L.P., because she was the one who organized the group every time, and when I turned on the computer, your email was waiting for me...

You have no idea how nice it is to hear words of thanks and appreciation, not because I need them, but because it proves we are on the right path. That you need these face-to-face meetings, something technology doesn't replace or give.

You were a full partner both in organizing the girls, often giving them a lift to and from the train, always coming on time, and attending all the meetings over three years! These things aren't trivial, they show seriousness, perseverance, and a desire to learn and give of yourself. The delicious, fancy refreshments you always bring, not offhand, but in a way we can see you invested time and thought in them. We didn't miss any of this, and I thank and appreciate you no less than your words of appreciation to me. It's also not obvious that a mother of four, who also works and studies, devotes time to a monthly social and professional meeting. I see good students and good new preschool teachers in our group, whom these meetings polish and improve. Both because they participate and can therefore unload themselves to others, and also because when someone talks about what is bothering them and doesn't just chew it over himself, that's already half the solution. Teachers have a teachers' room, but preschool teachers don't. This meeting is a kind of teachers' room for preschool teachers. And there are things you can't write about on WhatsApp. For example, despite all the jokes about Shira sending so many WhatsApp messages the story about the two mothers in her preschool who quarreled because their children were fighting and that one of them didn't send her daughter to preschool, and how Shira was really bothered as if the mother didn't rely on her, she certainly didn't tell you on WhatsApp because I can see you are hearing it for the first time. What can you do? Face-to-face meetings have different dynamics than virtual ones.

\section{$4.62015 / 16$}

Table 4. 2015/16

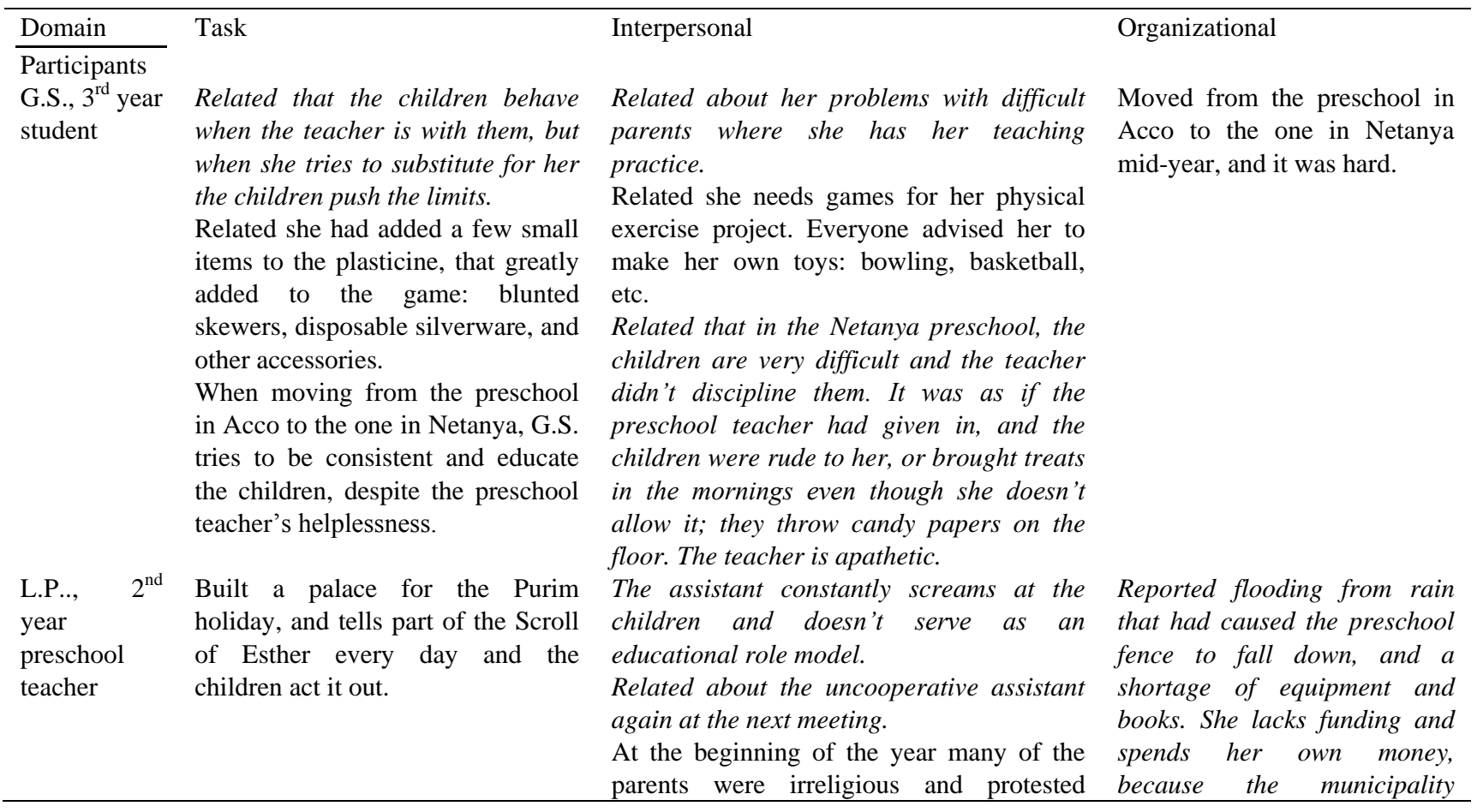


because there was no room at the secular preschool and came to her preschool fearing religious coercion. Now there is room, they want to continue with her, even next year.

Related about the hearing held between her and her assistant (municipality staff, preschool inspector, and Chair of the Association of Teachers' Assistants), it seems the assistant will not continue next year. During the hearing, the assistant denied everything L.P. said and there was an unpleasant atmosphere of one person's word against the other. However, L.P. said everyone saw the assistant spoke aggressively.

Likewise, she mentioned a new immigrant mother who criticizes everything and immediately turns to a lawyer and the inspectorate (e.g. she doesn't like Arab workers being in the yard so she decided that L.P. is "endangering the children"). Her son had already stayed at home for a few days and L.P. was upset.

At the same time, she contained the mother who has many children who she says is "an embittered woman who is constantly angry".

By the next meeting she related that the mother had returned her child to preschool, but wouldn't greet her.

Until the diagnostic team came to the preschool and saw the child had severe difficulties, and then L.P. decided to speak to the mother, despite her not speaking to her. Amazingly, the mother thanked her and was happy about the conversation.

When G.S. said she needed toys for her project, she immediately came to help her by lending her toys.

During the last, end of year, session, she complained again about the assistant, and said she was now nervous of confronting her, because she had discovered the assistant was from a crime family in the city.

N.A., $\quad 3^{\text {rd }}$ Careful about discipline and year boundaries with the children. The preschool results are satisfactory (she said teacher this repeatedly throughout two sessions).

She spoke about a successful Hanukah party with songs familiar to the parents, and likewise, related about a successful workshop she had arranged before the actual party.

N.M., $\quad 3^{\text {rd }}$ She related a successful activity year student mixing colors (that I observed) and a successful circle time about clouds and rain.
She sent the parents a guide for a New Year for Trees meal, and taught group members how to deal with parents: "Be assertive, don't let the parents 'get the better' of you, while also being polite and keeping the preschool rules".

When G.S. said she needed toys for her project, she immediately helped her by lending her toys.

During the final session she was barely present and busy with her cellphone, due to her wedding preparations. She summarized the year in that she had learned how to doesn't give enough. 
Shared her project about Sabbath liturgical songs and said that precisely because she is from a non-religious home, she liked the

N.N., $\quad 3^{\text {rd }}$ project and finds it challenging.

year student

T.L., $3^{\text {rd }}$ year

preschool

teacher

T.C., 3rd She related the story of a girl in the year student kindergarten where she is doing her teaching practice who couldn't eat solid food for medical reasons, and had to finish drinking cereal from a bottle every morning. The girl refused, and then T.C. invented a game for all the girls. As a result of the game, the girl finished her cereal every day.

Likewise, she shared a successful math game she had played, matching quantity to numbers grow from her failures.

mentor, who didn't praise her.

Ultimately she understood that it was actually this toughness that had strengthened her. It was she who approached the mentor and asked for feedback on the activities, until the preschool teacher began to provide feedback without N.N. asking.

N.N. was nervous if she would be given a preschool the next year, particularly because of working with parents.

She spoke about a problematic mother who wasn't cooperating regarding her son's difficulties, and T.L. felt the mother was neglecting the child to a certain extent. All of T.L.'s difficulty is in communicating with this mother for the good of the child. The mother is very busy with work, and anything needed for the child seems like a burden to her. Social services are also involved.

She compliments N.A., her son's preschool teacher, on being a good teacher who her son loves.

During the last session, she related they brought a very experienced preschool teacher to the preschool next to hers, and the French parents like her more because she does as the parents wish. T.L. thinks it is unfair to place an experienced teacher alongside a new one, because the parents make comparisons.

She offered a large spinning top to L.P. for the Hanukah party.

She related she has difficulty in the preschool where she is doing her teaching practice, because the teacher didn't give her enough feedback and direction. The preschool teacher is good, but the suffocatingly close relationship with T.C. bothers her a little.

When L.P. related that she had built a palace for the Purim holiday, T.C. wondered, "Why would you build Ahasuerus's palace in the preschool for Purim? If he had been a Jewish king, I could understand, but why would you perpetuate a palace from a foreign culture, that belonged to someone who oppressed the Jews?"
At the end of the year she related she hopes to move south. She finds the French immigrants very difficult and believes they "demand things with audacity, and don't understand Israeli mentality. I feel they dislike me, and I don't like them either."

\footnotetext{
Studying the research literature about self-efficacy shows that the concept has positive and significant correlation with many components of motivational behavior, that can indicate its importance as a critical predictor of motivational behavior and study. The studies unequivocally show that self-efficacy plays a role in predicting and mediating in the correlation between the number of components of ability (e.g. skills, knowledge, ability, or previous knowledge) and later achievements (Bandura, 1986; Pajares \& Schunk, 2002). Studies in this field were inconsistent. In contrast to
} 
studies that indicate that greater motivation accompanies "academic experience" (Linder \& Harris, 1993), other studies show a decline (Fisherman, Kaniel, \& Shay, 2000).This mixed trend also exists regarding differences between first and third year teaching students (Rich, Iluz, \& Kula, 2000).

In 2015/16, each of the participants proved her motivational behavior in all domains: the preschool teacher-parent relationship, and the relationship of the preschool teacher to children with special needs. But the greatest difficulties were seen in the teacher-assistant relationships. The reciprocal relationship between the preschool teacher and assistant is one of most significant factors that projects onto the the preschool climate. This connection is complex due to each having a different employer and different professional training, the teacher being defined as preschool director, and personal characteristics (Studeni, 1989).The teacher and assistant are the permanent preschool staff, and the school's functioning depends on the (best possible) emotional well-being of both. A preschool director who is wise enough to nurture the assistant's sense of belonging, efficacy, and autonomy, as a basis of her sense of self-value and emotional well-being, will enjoy constructive cooperation from her. Examining the reasons for conflicts between preschool teachers and assistants demonstrates that one of these components is missing for the assistants, resulting in poor functioning. The objects of the conflicts usually focus on partial performance or deviating from her role, such as: resistance to giving out "dirty" materials, avoidance of, or refusal to, promote the teacher's initiatives that require cooperation, focus on cleaning, obvious avoidance of, or opposition to, activities with the children under the teacher's guidance, using methods unacceptable to the teacher when working with children, or disclosing information to parents. Such situations, in which the educational staff is uncooperative, spoils the atmosphere, and leads to further difficulties in functioning.

The "couples" or "parenting" relationships attributed to the connection between the preschool teacher and her assistant make it difficult for the teacher to exercise her authority as director, and thus sometimes, concern not to harm the preschool's atmosphere actually prolongs situations of the assistant's disfunction, and prevents the teacher working according to her educational beliefs and performing the various aspects of her role as preschool director.

It can be seen from Table 4 that G.S., who exhibited high self-efficacy the previous year, experienced a small drop in her self-efficacy, particularly in the interpersonal and task domains. However, the reason is the low functioning of the preschool teacher where she is training - functioning that affects G.S.'s self-efficacy. N.M. remained with a medium self-efficacy level in the interpersonal domain, sharing less with the group members and speaking less about herself. L.P. also remained with a medium level of self-efficacy, when alongside her successes in the task domain with children, she experienced a sense of failure in the interpersonal domain with the assistant and parents. N.A. exhibited a high level of self-efficacy this year in all domains, and in this aspect she has increased her self-efficacy level since last year. T.C., who joined the group only this year, has a high level of efficacy in the task domain, and a lower level in the interpersonal domain with her mentor preschool teacher. N.N., who only joined this year, also has a mixed level of efficacy in the interpersonal domain - while she had hard feelings about her mentoring preschool teacher initially being tough with her, she later understood that it only strengthened her and this is a good insight into self-efficacy. However, she also expresses her concerns about the future, when she will be given a preschool next year and need to cope with the parents. Many studies have clarified and expanded the role of seeing self-efficacy as a mechanism present in the roots of behavioral change, conservation, and generalization. There are testimonies, for example, that self-efficacy predicts various future results (Bandura, 1986). This year of meetings, in which the group participants had time to become a team, develop and share, reflects the extensive difficulties in making decisions and difficult challenges, and the long process of improving self-efficacy they each underwent, a process that predicts each one's future in accordance with the level of self-efficacy they have achieved.

\subsection{A letter from N.N., Sent in April 2016}

I wanted to thank you for the wonderful evening. I felt I was given strength for the future, and I also felt safe in sharing my concerns with you. I gained a lot of strength from what was said, and I am taking the advice and educational tools for future use.

\section{Summary}

The findings in this article show that the monthly meetings contributed to intensifying most of the participants' feelings of self-efficacy, and therefore, this model of intimate sessions in a homely atmosphere can also be adopted for other groups of students, preschool teachers, and teachers.

The information in the tables shows that 2012/13 was mainly characterized by the struggles of students, 2013/14 by problems of preschool teacher-parental relationships, 2014/15 by the struggles of the challenges of the young teachers/ students on all the planes noted in previous years.

On the personal plane, S.D. stood out for her high sense of efficacy in all the parameters. In contrast, T.L.'s low self-efficacy was pronounced throughout the time period, and was expressed in her attitude towards the parents, inspector, 
and assistant, and their attitude towards her. The other participants ranged between medium to high self-efficacy, for example, N.A., L.P., N.M., and N.N. It also emerges that the participants with a high sense of efficacy made a positive change in the children's feelings. For example, S.D., regarding her success with the child who only uttered syllables, and T.C.'s success in giving the cereal to the sick child. Such preschool teachers also manage their classes in a manner that arouses autonomy among the children, and uses fewer threats and expressions of anger to achieve discipline. They have good partnerships with the parents and enlist their intervention to help the children. We also saw with analysis in the personal plane of one of the participants, that the key to change in the self-efficacy domain is motivation. Each student's motivation determined her student present and professional future. The encouragement, tools, and support each participant received from me during the sessions only helped her when she had the inner motivation to listen, internalize, and desire to change. Whoever gave up from the start did not survive the journey.

Regarding the interpersonal domain, the reciprocal component emerging from the findings should be noted. Preschool teachers and students with a high sense of efficacy influenced others (peers, children, and parents). We saw the students and teachers shared their activities during the meetings, and offered to lend - or even give - each other materials.

Soodak and Podell (1996) argued that the working conditions of teachers with a low sense of efficacy for results must be changed: many capable teachers with a high sense of self-efficacy regarding their teaching abilities work under conditions that hinder their efforts, and therefore develop a low sense of efficacy regarding results, and lose their motivation to teach. During the final year T.L., who has lower self-efficacy, wants to move south where, "I won't have to work with French parents, who dislike me, and I don't like them." It can be said that in light of Bandura's studies that opine that self-efficacy is gradually formed by learning stemming from interaction between the environment, the individual's motivational mechanisms, and his or her achievements, that this theory was realized among the group: they gradually learned, while simultaneously participating in the group interaction and their own achievements. Self-efficacy is not a characteristic of personality, but a situational belief regarding the field of specific content. Meaning, a person has different self-efficacy levels relating to different aspects of his life - like the self-efficacy level in various domains of his personal life, a person feels a particular level of self-efficacy in the general area of his professional life. The learning process is not only a dialogue between a person and his environment and those around him, but also between a person and himself (Katz \& Frish, 2013). Dialogue is a learning framework that enables every teacher to expand and improve the knowledge that is recreated. Reflective dialogue increases the learner's awareness for self-criticism regarding the process and result. Experimenting and personal reasoning are exposed to other people's criticism, and thus new links are created, concepts updated, and more consolidated and strengthened structures are constructed (Silberstein, Ben-Peretz, \& Ziv, 1998). Students at various levels help each other develop reasoning skills. Peer teaching, learning, and evaluation, create a learning community with all its components.

This article has examined these aspects using three parameters - task, interpersonal, and organizational, and we have discovered that there are sometimes gaps in the self-efficacy of one of the participants from one parameter to the other, and sometimes high self-efficacy in one parameter testified to, and influenced, similar self-efficacy in other parameters. Due to recognition of the importance of the task, interpersonal, and organizational domains for teaching effectiveness, the heads of college departments of early childhood education must examine to what extent preschool teaching students are prepared to develop and use these characteristics. How much do the early childhood education programs impart reasoning and team work skills? Are the students in this track taught how to communicate with parents, and the skills to view the child as a person who needs his sense of study efficacy strengthened? After this examination of the preschool teacher training curriculum, we need to improve what exists and add what is missing.

\section{References}

Almog, O., \& Shechtman, Z. (2004). Teachers' instructional behavior towards students with special needs in regular classes and their relationship to students' performance. Sugiot Behinukh Meyuhad U-Veshikum, 19(2), 79-84.

Ashton, P. A., \& Webb, R. B. (1986). Making a difference: Teachers' sense of efficacy and student achievement. New York, NY: Longman.

Bandura, A. (1986). Social foundations of thought and action: A social cognitive theory. Englewood Cliffs, NJ: Prentice-Hall.

Bandura, A. (1997). Self-efficacy: The exercise of control. New York: Freeman. https://doi.org/10.1007/978-1-4615-5843-9

Barone, D. F., Maddux, J. E., \& Snyder, C. R. (1997). Social cognitive psychology: History and current domains. NY and London: Plenum Press.

Cherniss, C. (1993). Role of professional self-efficacy in the etiology and amelioration of burnout. In: W.B. Schaufeli, C. Maslach, \& T. Marek (Eds.), Professional Burnout: Recent developments in theory and research (pp. 135-150). 
Philadelphia, PA: Taylor \& Francis.

Cohen, E., \& Leyser, Y. (2004). Teachers' attitude toward inclusion according to the disability's category and graveness, and their perception of skills needed for coping with students with disabilities in the inclusive classroom. Iyun Umekhkar, 15, 19-38.

Fisherman, S., Kaniel, S., \& Shay, A. (2001). Time management and managing self-learning of students. Dapim, 31, 57-79.

Friedman, I. A., \& Kass, E. (2000). Teacher self-efficacy: The concept and its measurement. Jerusalem: Henrietta Szold Institute.

Hyson, M. (Ed.) (2003). Preparing early childhood professionals: NAEYC's standards for programs. Washington, DC: National Association for the Education of Young Children.

Kaplan, A., \& Asor, A. (2001). Motivation for studying in school - In practice. In A. Asor, \& A. Kaplan (Eds.), Teaching thinking 20. Jerusalem: Branco Weiss Institute.

Katz, S., \& Frish, Y. (2013). Self-efficacy: From theory to practice. Haifa: Shaanan College.

Linder, R. W., \& Harris, B. (1993). Self- regulated learning: Its assessment and instructional implications. Educational Research Quarterly, 16, 29-37.

Pajares, F., \& Schunk, D. H. (2002). Self and self-belief in psychology and education: An historical perspective. In: J. Aronson, \& D. Cordova (Eds.), Psychology of education: Personal and interpersonal forces (pp. 121-167). New York, NY: Academic Press. https://doi.org/10.1016/b978-012064455-1/50004-x

Rich, Y., Iluz, S., \& Kula, A. (2000). The positions of students of education at institutions for research in education and its application in a changing world. Paper presented at Elah - The Conference of the Israeli Organization for the Study of Education.

Ruijs, N. M., \& Peetsma, T. D. (2009). Effects of inclusion on students with and without special educational needs reviewed. Educational Research Review, 4, 67-79. https://doi.org/10.1016/j.edurev.2009.02.002

Shimoni, R., \& Baxter, J. (1996). Working with families: Perspectives for early childhood professionals. Don Mills: Addison-Wesley.

Silberstein, M., Ben-Peretz, M., \& Ziv, V. (Eds.). (1998). Reflection in teaching: A central axis in teacher development. Tel Aviv: Mofet Institute.

Soodak, L. C., \& Podell, D. M. (1996). Teacher efficacy: Toward the understanding of a multi-faceted construct. Teaching and Teacher Education, 12(4), 401-411. https://doi.org/10.1016/0742-051X(95)00047-N

Studeni, M. (1989). Together and separately: Preparation by the pre-school teacher and aide for working during the school year. Hed Hagan, 3, 24-29.

Talmor, R., Reiter, S., \& Feignin, N. (2004). Factors relating to regular education teachers' burnout in inclusive education. Sugiot Behinukh Meyuhad U-Veshikum, 19(1), 17-31.

Timor, T. (2004). Physical inclusion yet curricular exclusion? School staff perceptions of the curriculum for students with learning disabilities in mainstream secondary schools in Tel-Aviv, Israel. Sugiot Behinukh Meyuhad U-Veshikum, 19(2), 5-16.

\section{Copyrights}

Copyright for this article is retained by the author(s), with first publication rights granted to the journal.

This is an open-access article distributed under the terms and conditions of the Creative Commons Attribution license which permits unrestricted use, distribution, and reproduction in any medium, provided the original work is properly cited. 